\title{
CONFORTAMOS? LIDAMOS COM O HUMANO SEM CONHECER O QUE DE HUMANO TEMOS DENTRO DE NÓS
}

\section{DO WE COMFORT? WE DEAL WITH HUMAN BEINGS WITHOUT BEING AWARE OF OUR HUMANNESS}

Fernanda Carneiro Mussi *

\begin{abstract}
MUSSI, F.C. Confortamos? lidamos com o humano sem conhecer o que de humano temos dentro de nós. Rev. Esc.Enf.USP, v.33, 11.2, p.113-22, jun. 1999.
\end{abstract}

\section{RESUMO}

Faço um convite à. reflexão propondo um confronto entre o que pensam, esperam e precisam alguns pacientes e familiares quanto ao conforto e comportamentos habituais adotados pelas pessoas do sistema de atendimento nas interações com seus clientes. Se o conforto, na perspectiva dos clientes, está associado a uma prática humanística que comportamentos profissionais podem se constituir em. obstáculos para a sua promoção? A reflexão se estende a compreensão de fatores que influenciam os comportamentos profissionais e a. identificação de possiveis caminhos para. a promoção de um prática humanistica.

UNITERMOS: Humanismo. Cuidados de conforto. Relações enfermeiro-paciente.

\begin{abstract}
Reflections are intended to propose a, confrontation between patients and families' thoughts, expectations. and needs regarding comfort and the usual behaviors adopted by health care agents during their interactions the clients. If comfort as viewed by patients is seen as a humanistic practice, which professional attitudes can become an obstacle to comfort? Reflections are also associated to factors that determine professional behaviors and the identification of the paths for a. more humanistic practice.
\end{abstract}

UNITERMS: Humanism. Care comfort. Nurse-patients relations.

\section{Introduzindo!}

Desde o final do século passado com NIGITINGALE (1859) até o momento atual o tema conforto está inserido nos livros textos de enfermagem com ênfase dada as medidas de promoção, manutenção e restauração do conforto (GOODNOW . 1950; HORNEMANY, 1977; FRANCIS; MUNJAS, 1979; ELHART et al. 1983; DU GAS, 1984; KAWAMOTO; FORTES, 1986 ; SORRENTINO, 1987) e vem sendo considerado por autores nacionais e internacionais como um conceito fundamental e relacionado à prática da enfermagem (ARRUDA et al. , 1992; JACOX, 1989; MORSE, 1994;), como um objetivo a ser atingido pela assistência de enfermagem (ORLANDO, 1978;
AMERICAN NURSES' ASSOCLATION, 1980 e BOTTORFF s.d., como processo e produto da prática dia enfermagem (MORSE, 1994; KOLCABA, 1995).

Alguns pesquisadores têm procurado comprender a experiência do conforto na ótica de pacientes utilizando uma variedade de abordagens qualitativas. Estes estudos consistem em esforços importantes para a compreensão desse fenômeno e para a construção de uma estrutura teórica.

Considerando que as ações de enfermagem devem procurar responder às expectativas e necessidades de nossos clientes, precisamos conhecer sobre aquilo que é preciso, essencial, indispensável para o seu conforto e no que relacionam-se à

\footnotetext{
* Aluna o Programa de Doutorado de EEUSP.
} 
assistência de enfermagem. Partindo dessa premissa aliada ao desconhecimento do fenômeno conforto para pacientes em estado crítico e seus familiares MUSSI (1994) ; OLIVEIRA; MUSSI (1996) procuraram compreender as necessidades de conforto diante dia situação de ameaça à vida e de ruptura com o cotidiano enfrentada por eles face à doença e hospitalização. Os resultados desses estudos mostraram que o conforto é obtido por ações e intenções de diversas pessoas do sistema de atendimento e familiar e salientaram a importância de uma abordagem profissional ético-humanística para a promoção do conforto.

Contudo, parece-me que as condições sob as quais estabelecemos as interações com os pacientes e familiares, muitas vezes podem negar a vivência da experiência do conforto, ou seja, necessidades, desejos e expectativas dos nossos clientes podem ser frustados se adotarmos atitudes que os desqualificam como seres humanos.

Desta forma, neste trabalho, faço um convite à reflexão propondo um confronto entre o que pensam, esperam e precisam alguns pacientes e familiares quanto ao conforto e comportamentos habituais adotados pelas pessoas do sistema de atendimento, nas interações com seus clientes, que podem se constituir em obstáculos para a experiência de conforto. A reflexão se estende à compreensão de fatores que influenciam os comportamentos profissionais e à identificação de possíveis caminhos para a promoção de um prática humanística.

Tendo esta finalidade procedo dia seguinte maneira: Primeiramente apresento a análise de alguns dados extraídos de entrevistas feitas para duas investigações. A primeira foi realizada por MUSSI (1994) e verificou os significados e necessidades de conforto na perspectiva de pacientes com infarto agudo do miocárdio. A autora utilizou instrumento específico para entrevistar 25 indivíduos adultos do sexo masculino internados numa unidade coronariana, num hospital governamental do município de São Paulo. A segunda focou sobre o significado de conforto expresso por 15 familiares que tinham um de seus integrantes em estado crítico hospitalizado num Centro de Terapia Intensiva no município de São Paulo (OLIVEIRA; MUSSI, 1994). Tais dados foram extraídos porque mostraram a importância de uma abordagem ético-humanística para a promoção do conforto. Após esta etapa, descrevo atitudes profissionais que observei no decorrer de meu exercício profissional, na dinâmica de assistência hospitalar, as quais podem se constituir em obstáculos para a promoção do conforto. Na sequência analiso alguns determinantes dos comportamentos profissionais e suas implicações, utilizando referenciais da psicologia, entre eles,
BION (1969); FORNARI (1989); MENZIES (1970); MONEY-KIRLEY (1969); RODRIGUES (1991), TASSARA; DAMERGIAN (1996), e da enfermagem (CIAVES; IDE, 1994; IDE, 1991, 1995), e aponto caminhos para a promoção de uma prática mais humanística.

\section{Compreendendo as expressões dos pacientes e familiares relacionadas ao conforto!}

As demonstrações afetivas das pessoas do sistema de atendimento dirigidas aos pacientes e familiares foram associadas à experiência do conforto. Terem valorizado a qualidade das interações pessoais evidenciou que o conforto relaciona-se à percepção de que as pessoas estão comprometidas com eles e interessadas nas suas necessidades e que se sentem aceitos e valorizados como seres humanos. O conforto, nesse sentido, emerge como produto de uma prática humanitária, de um processo de confortar que requer uma abordagem humanística daqueles envolvidos com os pacientes. Ele pode surgir nos relacionamentos com aqueles que cuidam de nós.

"Gosto muito do conforto. É fundamental em todas as situações especialmente nesta que significa a solidariedade, a atenção e o carinho do pessoal que cuida de mim". (Márcio, 53 anos - paciente)

"Muitos médicos, muitos enfermeiros
esquecem desse lado humano, de
afetividade, de cuidar da parte
emocional dos parentes, isso ajuda
muito"... (Maria, 37 anos-'familiar)

Familiares manifestaram que para estarem confortáveis precisavam estar assegurados de que os pacientes recebiam demonstrações afetivas, tinham preservada a sua individualidade e estavam em um ambiente hospitalar familiar. Nesse sentido, o conforto relaciona-se às expectativas dos familiares de que os profissionais que prestam assistência reconhecem os pacientes como pessoas, são capazes de compaixão e de respeitar as especificidades dos individuos, apesar do âmbito altamente técnico de cuidado à saúde.

"Conforto não é só técnica, a questão é o quanto o paciente está recebendo afeto, atenção, carinho. Não é só estarem olhando para o rim dele que parou"...(Jorge, 58 anos-familiar)

"Quem está na. UTI, você não reconhece, não tem. nada. Nada é da pessoa". (Josefa, 37 anos - familiar) 
Pacientes expressaram que o afastamento ou ausência de pessoas significativas para eles durante a hospitalização interferia no seu conforto. Familiares relataram que para sentirem-se confortáveis era necessário estarem perto, ao lado, junto do paciente transmitindo força e coragem e ressaltaram a expectativa de flexibilidade dos profissionais frente às normas e rotinas que regem

o contexto das Unidades de Cuidados Intensivos possibilitando-os a estarem mais próximos de seus entes queridos. BOTTORFF (s.d.) reforça a importância do envolvimento entre a família e o paciente, para o conforto de ambos, ao questionar: "como alguém tolerará o sofrimento e a dor sozinho... os indivíduos diante da posição de vulnerabilidade e dor na doença, adquirem um senso renovado do valor dos outros, tornam-se abertos e desejam que as pessoas estejam próximas, mesmo quando não admitem isto claramente a princípio... quando não são confortados, não tem mais condições de se apoiar em seus recursos interiores, precisam buscar ajuda de outros, força para que não caiam no desespero. $\mathrm{O}$ ambiente hospitalar pode tornar-se mais familiar ao adaptarmos as normas e rotinas hospitalares às necessidades dos pacientes e seus acompanhantes.

"Me falta estar com aqueles que tenho intimidade, as pessoas da família, os amigos que podem me confortar nesse momento".... (Paulo, 54 anos - familiar)

"É eu poder dar toda a. assistência pra ele, dar força né; ficar do lado dele a hora que ele mais precisa, ou toda hora, desde a hora que ele entrou"... (Marina, 45 anos - familiar)

"Na. medida. que não atrapalhe o andamento da enfermagem, do atendimento, do paciente, que não sejam muito rígidos, quer dizer, que sejam flexiveis, permitir a. visita na UTI, que mais de uma pessoa entre de cada, vez" (Monica, 35 anos - familiar)

A preservação da individualidade e o respeito à privacidade o paciente e do familiar, pela equipe de saúde, foram expressadas como essenciais ao conforto representando para eles o reconhecimento das pessoas que prestam assistência de que são pessoas e não objetos, de que têm identidade, necessitam ser considerados em suas especificidades e não invadidos em seu território.

\footnotetext{
"Usar essa camisola... ela não me protege... ire deixa exposto para os outros" (Jorge, 50 anos - paciente)
}

"Sentir que está um pouco em casa, se a gente não tiver identidade... está abandonado, se a gente não se reconhecer dentro do local... está abandonado... (Sérgio, 38 anos familiar)

Os pacientes relataram também que o conforto estava associado ao atendimento imediato às suas solicitações e a serem questionados sobre aquilo que precisavam Assim, a identificação das necessidades e preferências dos pacientes e tentativas profissionais para ajustarem-se a elas representam uma maneira de reduzir o sentido de inflexibilidade da rotina hospitalar, de preservar o sentimento de poder e utilidade dos pacientes e de promover conforto.

"Quando eu chamo e eles vêm eu me sinto seguro e confortável... mas quando aguardo... chamo e toco... chamo $e$ toco ...e nada ....é como se estivesse só" (Carlos, 42 anos - paciente)

"Fico confortável quando perguntam pra mim, se quero, se prefiro fazer alguma coisa de um jeito diferente... (Pedro, 52 anos -paciente)

Familiares descreveram que precisavam conhecer e receber informações particularizadas sobre a evolução o cuidado e tratamento do paciente e terem facilidade de acesso e de comunicação com os profissionais de saúde para estarem confortáveis:

"As informações são muito secas, qualquer um que ligue, ou numa visita de rotina, olha, está estável. Está estável, e nada, pra mim dá o mesmo, então, eu acho que deveria ter informações mais embasadas... alguma coisa que te deixe mais tranquilo em casa" (João, 34 anos)

"Explicar passo a passo, se a pessoa está grave porque é que está grave"...Explicar pra gente entender o que está acontecendo... (Marisa, 34 anos)

"Ter acesso às enfermeiras, porque eu acho muito importante. Você ficar num lugar que dificulta não poder falar com o enfermeiro ou com alguém, não é legal..." (Júlia, 53 anos)

\section{Descrevendo as atitudes profissionais contrárias à vivência do conforto!}

Não são raras as vezes em que nos deparamos com cenas de pacientes caminhando por corredores 
Confortamos? Lidamos com humanos sem conhecer o que de humano...

Fernanda Carneiro Mussi

hospitalares com camisolas curtas e abertas expondo seus corpos e sua intimidade sem nos sentirmos incomodados com o que vemos. Tudo soa estranhamente natural. A invasão do corpo e do território da pessoa não é incomum: dela nos aproximamos e, sem pedir consentimento ou justificar a finalidade, começamos a despir e a tocar seu corpo. Manipulamos seus pertences, trocamos de um lugar para outro sem pedir licença ou indicar o que queremos. Geralmente, não há espaço para a preservação de um objeto de identificação e valorizado pelo paciente e, assim, o ambiente tornase sombrio e entediante e nele a pessoa não se reconhece.

Ao se internar o paciente é destituído de tudo - roupas, objetos. nome - e a ele, muitas vezes, ditamos o proibido e o permitido, enquadrando-o nos códigos de pertinência da rotina hospitalar, restando-lhe como saída a obediência e a submissão.

Não há ouvidos para o desejo de não querer tomar banho na madrugada de cada dia. A resposta reiterada é: essa é a rotina aqui. O banho prepondera a tudo.

O acesso do familiar ao paciente esbarra na burocracia soberana aos seus sentimentos, necessidades e desejos. Pacientes sofrem e morrem sozinhos porque diante da dor e da solidão as pessoas significativas à eles são substituídas pela hora do banho, pelo regulamento de visita, pela limpeza da unidade, pelos humores profissionais... Nem sequer consideramos as razões expressas pelos familiares e pacientes, ouvimos o que queremos e olhamos com nossas lentes, se ainda somos capazes de perceber alguma coisa.

Ainda que não bastasse, a perpetuação da coerção se faz pelo discurso cientifico. Palavras soam como impróprias e incompreensíveis porque em geral não fazem parte do conhecimento de mundo dos familiares e pacientes. Boletins de informações genéricos sobre o estado do paciente são emitidos em "chavões" - grave, estável, regular - que não traduzem as particularidades de um estado e de uma evolução mas, apenas intensificam a angústia e a impotência dos sujeitos e negam a possibilidade de conscientemente participarem do processo de tomada de decisão sobre o seu cuidado e tratamento. A expectativa pela orientação culmina na frustação e ansiedade pela incompreensão.

Pregamos a importância da visita aos doentes, no entanto quando acontece cabem questões como Urinou? Evacuou? Dormiu bem? Deixa ver o curativo (já mexendo)? - ou ordens- O senhor não pode fazer essas e ,essas coisas. São, as vezes, esvaziadas de avaliações e interações que possibilitam o julgamento clínico das necessidades de cuidado do paciente e da intenção de um envolvimento que permita, pelo menos, uma aproximação da compreensão da experiência vivida pelos pacientes. A produção em série, a fragmentação do cuidado e a maximização da tarefa eliminam a individualidade do sujeito e o estabelecimento de vínculos.

Pouco percebemos a disponibilidade profissional para ouvir o paciente, mesmo quando ele apela com tentativas incessantes pelo toque da campainha. Toleramos o seu som estridente e repetitivo, mas postergamos o atendimento da chamada e nem sempre justificamos de imediato a impossibilidade de estar lá naquele momento. Das chamadas repetitivas decorrem rótulos como paciente manhoso, dependente, mimado, rebelde.

Diferentes profissionais indagam aos pacientes, repetidas vezes, sobre a mesma coisa e eles continuam sem compreender o propósito das questões. São convidados a responder um roteiro de questões cuja linearidade imposta abole o espaço para expressarem-se livremente.

As expectativas, vontades, angústias da família nem sempre são ouvidas ou identificadas e quando esboçamos intervir junto a ela o fazemos mediante audição seletiva. Estar ocupado, desviar o olhar, negar ou postergar informações consistem em algumas respostas as diversas tentativas dos familiares para comunicarem-se conosco. A família pode ser ignorada, subestimada e infantilizada.

Com base nestas descrições, depreende-se que embora a promoção, manutenção e restauração do conforto dos nossos clientes sejam pregados e defendidos na prática e teoria da enfermagem e valorizados por eles, podemos estar distantes de tornar esta meta uma realidade.

\section{Procurando analisar a determinação desses comportamentos e suas implicações}

Como somos capazes de obliterar as fronteiras daqueles que cuidamos e desqualificar o humano?

Sem o intuito de justicar nossa desumanidade, sabe-se que a nossa coerção sobre os doentes decorre de mecanismos de defesa que utilizamos para enfrentar o sofrimento psíquico inerente às características do processo de trabalho e da dominação exercida sobre nós na vivência das relações com os representantes do poder institucional (o poder médico,- o poder das instâncias deliberativas, o poder normativo) e do desejo consciente ou inconsciente de exercermos poder sobre outras pessoas.

RODRIGUES (1991) nos coloca que "quanto à tarefa primária, o cuidado de doentes, sabemos quanto ela é intrinsicamente ansiogênica. O contato 
quotidiano com o sofrimento, com corpos mutilados, com a morte, mobiliza as ansiedades mais primárias do ser humano: as ameaças, fantasias e culpas da fase oral, isto é, a maior regressão possível. Aprendemos com Izabel Menzies, que viver seguidamente tais condições objetivas instaura no indivíduo o estado de mente representado pelo modelo da equação simbólica, isto é, a confirmação, pela realidade, das fantasias mais terrorificas vividas na fase das primeiras relações objetais".

Lançaríamos, então, mão de mecanismos de defesa, entre eles, a fragmentação do relacionamento enfermeiro-paciente e a despersonalização, a categorização e negação da importância do indivíduo e a racionalização de sentimentos. Como o fulcro da situação de ansiedade para o enfermeiro reside na sua relação com o paciente, para evitá-la fragmentase o relacionamento enfermeiro-paciente restringindo o seu contato com eles e converte-se os pacientes que necessitam de enfermagem em tarefas que devem ser executadas. Uma enfermeira tornase um aglomerado de técnicas de enfermagem, sem individualidade. Isso a previne de entrar efetivamente em contato com a totalidade de cada paciente e sua doença, e oferece alguma proteção contra a ansiedade que esse contato mobiliza (MENZIES, s.d.).

"A proteção advinda do sistema de lista de tarefas é reforçada pela despersonalização ou eliminação dias diferenças individuais tanto na enfermeira como no paciente. Por exemplo, as enfermeiras frequentemente se referem aos pacientes, não pelo nome, mas pelo número do leito ou pela doença ou órgão doente, "o figado do leito 10 "ou a "pneumonia do leito 15". As próprias enfermeiras depreciam esse hábito, mas ele se mantém. A maneira pela qual um paciente é tratado é amplamente determinada pela sua pertinência a uma categoria de pacientes e minimamente pelos seus desejos e necessidades idiossincráticos. Consequentemente, só existe uma maneira de arrumar a cama, exceto quando a doença física requer outra: uma hora determinada para lavar todos os pacientes" (MENZIES, s.d.).

Decorre que tanto o enfermeiro quanto o paciente são privados de satisfações positivas, o primeiro pelo reasseguramento que viria da confiança na competência em enfermagem e o segundo pelo sentimento de consideração e desejo pelo seu bem-estar. Percebo o paradoxo que se instaura quando MENZIES (s.d.) analisa que "a ansiedade e a culpa são estimuladas quando o enfermeiro no exercício profissional falha no uso de sua plena capacidade a serviço de outras pessoas necessitadas. As enfermeiras acham as limitações de seu desempenho muito frustadoras. Elas frequentemente sentem uma dolorosa sensação de fracasso quando executaram rigorosamente suas tarefas prescritas e expressam culpa e preocupação em relação a incidentes nos quais elas seguiram as instruções ao pé da letra, mas, ao fazê-lo, praticaram o que elas consideram má enfermagem".

Encontramos também na institucionalização das práticas de saúde reforço para a fragmentação da relação enfermeiro-paciente. "A institucionalização das práticas de sáude insere o médico com o papel claramente definido de curar, pautado na relação dual profissional-paciente e, a inserção da enfermagem como a profissão responsável pela disciplina do serviço de prática da saúde visando dar sustentação às demandas médicas, tendo sua atuação pautada no controle do ambiente iluminação, higienização e aeração; no controle das pessoas e de tempos e movimentos- estabelecendo local, horário e ritmo de trabalho e no controle do processo de formação determinando padrões de conduta moral e atuação profissional" (IDE, 1995). Assim, a sociedade se apropria das demandas psíquicas dos que cuidavam para responder às demandas sociais e institucionais minimizando a necessidade de cuidar através da substituição por funções que não dominam o cuidar, mas apenas o tangenciam, determinando um desvio primordial do papel do enfermeiro que se estende até os dias de hoje. O afastamento do doente resulta na quebra do contrato simbólico inicial (preciso ser cuidado. posso cuidar) estabelecido no momento da admissão entre o enfermeiro e o paciente, promovendo a cisão de fantasias e gerando conflitos. Ambos experenciam sentimentos de traição, injustiça e abandono, conferindo maior sofrimento e induzindo à elaboração mútua de mecanismos de defesa, frente a essa situação (CHAVES; IDE, 1994) .

O estudo de JAQUES (1969) nos mostra que as instituições funcionam como mecanismos de defesas para as angústias persecutórias e depressivas e que a resistência de um grupo à mudança social decorre do fato das mudanças ameaçarem as defesas sociais existentes contra ansiedades profundas e intensas. Desse modo, MENZIES (s.d.) compreende que "o serviço de enfermagem cujo trabalho estimula tais ansiedades primitivas e intensas, iria antecipar a mudança com uma ansiedade excepcionalmente severa. A fim de fugir dessa ansiedade, o serviço tenta fugir da mudança na medida do possivel, poderíamos dizer que a qualquer preço, e tende a agarrar-se àquilo que é conhecido mesmo quando o conhecido evidentemente cessou de ser apropriado ou importante. As mudanças tendem a ser iniciadas somente quando se chega à crise". "O traço característico do sistema social de defesa é sua orientação em auxiliar o indivíduo a fugir da ansiedade, culpa, dúvida e incerteza. Tanto quanto 
possivel isso é feito através dia eliminação de situações, acontecimentos, tarefas, atividades e relacionamentos que causam ansiedades relacionadas com remanescentes psicológicos da personalidade. Faz-se muito pouca coisa positiva para ajudar o individuo a confrontar-se com as experiências que evocam ansiedade e ao enfrentá-las desenvolver a capacidade para tolerar e lidar mais efetivamente com a ansiedade" (MENZIES,

s.d.).

Segundo 'PASSARA; DAMERGIAN (1996) "é na relação mãe-bebê que o vínculo de poder se inicia, dada a absoluta dependência que nós seres humanos, temos com relação aos primeiros objetos (mãe ou substituta) que nos asssistem, sem os quais não sobreviveriamos. Apesar de nossa pretensa onipotência, estamos completamente à mercê das condições impostas pelo meio que nos circunda. E mais: sujeitos a identificar-nos com nosso agressor quando oprimidos por um objeto agressivo (como mostra Anna Freud), em uma tentativa desesperada de apaziguarmos o objeto, buscando evitar ou reduzir o mal estar criado com a opressão. A imitação física ou moral da pessoa do agressor, ou ainda, a adoção de seus símbolos de poder confirmam a necessidade de eliminar a diferença que denuncia a ameça. Inconscientemente, tentamos ficar iguais ao agressor para não sucumbirmos diante dele. O homem traz. então, como modelo em sua vida mental um vínculo de poder e vai repeti-lo na vida social, procurando estabelecer uma relação dominador-dominado, já inscrita em seu inconsciente. Ao voltar-se para o externo, para o mundo social em busca de satisfação de suas necessidades e desejos, o homem já possibilita ao outro o estabelecimento desse vínculo, construindo relações de amor e ódio, de gratificações e frustações, de troca ou jogo e manipulação, através das quais sua identidade se constitui". Com base no descrito poderíamos dizer que submetidas e submissas aos representantes do poder institucional nos aproximariamos deles por imitação como modo de diminuirmos a nossa visibilidade e necessitaríamos de pessoas submissas a nós para perpetuarmos o poder. A coerção pode recair. então, sobre os mais fragilizados, pacientes e familiares. Em consequência, os pacientes são despojados de seus pertences pessoais, submetidos a ritmos e tempos hospitalares (horário do banho, das refeições, de controles) e o acesso ao familiar é interditado. As informações são controladas, a dor não pode ser sentida fora do horário de medicação, forçadamente as suas emoções são racionalizadas. Admitimos o sofrimento na solidão. Os pacientes tornam-se propriedade dos profissionais, deixando de ter família, de ser uma pessoa e ter uma identidade.

Percebe-se no ritual de ajustamento do paciente às normas e rotinas do hospital ou seja, a aceitação dos valores da instituição como seus, descritos por IDE (1991), a identificação projetiva e introjetiva descritas por Melanie Klein apud BION (1969): "rotinas são veiculadas pelos profissionais, como sendo indispensáveis ao bem estar do doente e , consequentemente, ao do hospital. Assim, interesses institucionais e individuais se confundem, sendo obtido, como resultado, uma forma de cooperação tida como voluntária". Projetamos no paciente a importância de adesão às normas e rotinas corno sendo indispensáveis para o seu bem-estar, mas no entanto são indispensáveis para a nossa defesa e o paciente introjeta as projeções sob o risco de ser penalizado. A sacralidade definida por FORNARI (1989) como o máximo de positividade acompanhada de um mínimo de verificabilidade evidencia-se no valor atribuído aos esquemas normativos.

Aprendemos com FROMM (1972) que as pessoas que ousam discutir as normas ou as regras, contestar o consenso da minoria que detém o poder, estão predispostas ao ostracismo e à loucura. É necessário que o consenso da maioria manipulado pela minoria que detém o poder seja mantido para que o poder possa ser perpetuado. Nesse sentido o que está de acordo com a maioria é subjetivamente experimentado como real, verdadeiro, racional, moral. O consenso é, portanto, capaz de transformar o imoral em moral, o irracional em racional, o belo em feio. A repressão como já dito, recairia sobre os mais fracos e vulneráveis. A repulsa ao indivíduo que critica a realidade hospitalar aparece exemplificada por IDE (1991): penas, sutis ou não, são aplicadas como "incentivo à.adaptação": redução ou supressão de visitas, proibição do acesso à recreação, proibição de licenças, dentre outras formas de coerção... Não por acaso, a sintese desse processo determina o surgimento de um paciente resignado, dependente, submisso e passivo". Determinaria ainda mais o nosso distanciamento do paciente e da família considerados sob a nossa ótica rebeldes e inadaptados. Para FROMM (1972) a ansiedade é o motivo principal que obrigaria as pessoas a obedecerem e a se adaptarem.

Aprisionados à burocracia no contexto organizacional controlamos e enquadramos os nossos clientes e os esvaziamos de desejos, de condições cognitivas, psiquicas, sociais e culturais. Arendt apud COSTA (1991) nos diz que a "burocracia é sempre um governo de peritos, de uma minoria experiente, que tem de resistir da melhor maneira possivel à constante pressão da maioria inexperiente e FROMM (1972), como relatei, menciona que grande parte do que acreditamos ser verdade é apenas o consenso da maioria manipulado pela minoria que detém o poder. Trazendo essas 
concepções para a análise da realidade do contexto hospitalar podemos entender que ela pode ser editada pelos interesses dos dirigentes e pelos mecanismos de defesa dos profissionais que lá atuam e consensualmente aceita (com o viés da manipulação) pelos clientes, fragilizados diante da situação de vulnerabilidade e dor na doença, os quais concebem essa realidade como um mal necessário e transtorno que permitirá o retorno à vida normal.

A impotência- dos clientes na tomada de decisões sobre o curso do tratamento decorre também do uso da linguagem científica, frequentemente impossibilitada de ser decodificada por eles. A relação dominador-dominado, se institui novamente, mediada pela liguagem cientifica, representando um filtro social capaz de manipular o querer dos clientes e a realidade e tornar os atos e incoerências profissionais imunes a crítica e fortes no monopólio da vida alheia. Segundo TASSARA; DAMERGIAN (1996) "refletir o desejo do povo é uma proposição que se inverte e toma sentindo oposto: indicar ao povo quais são os seus desejos".

$\mathrm{Na}$ medida em que não pactuamos expectativas, possibilidades e limites com os familiares e pacientes perpetuamos relações de poder. Cumpre relatar que a gama de ações instituídas por aqueles que prestam assistência geralmente não são pactuadas com os clientes. $\mathrm{O}$ profissional concebe-se como aquele que detém e impõe o saber-fazer e o paciente como aquele que adere às decisões profissionais, porque nem sempre está instrumentalizado, minimamente, com informações assimiláveis para guiar-se nas possiveis opções de tratamento. Assim, o controle mediado pela linguagem assegura a eficácia do discurso da minoria que detém o poder. Ademais, a onipotência profissional é revelada no desejo e prazer que alguns profissionais têm de manter sob seu domínio as informações, nas caligrafias ilegiveis presentes nos prontuários e receituários médicos e nos boletins de informação.

Os significados da vivência da hospitalização para os pacientes e familiares podem estar adquirindo pequena relevância para os enfermeiros

e certamente diferindo entre os sujeitos, demandariam a especificidade de intervenções. Não é possivel ignorar esta premissa para manter a padronização de ações mesmo que destituídas de justificativa.

Notamos que o "discurso de racionalização, forma de perversão da razão" (TASSARA; DAMERGIAN, 1996) pode estar presente desde o início da formação do enfermeiro. NASCIMENTO (1991) aborda que já no processo de formação, o acadêmico de enfermagem vê desfilar diante de si uma série de imagens do corpo transmitidas pelas diversas disciplinas curriculares: o corpo máquina, o corpo-doença, o corpo falante da doença. Para a autora "em todas essas imagens o que verdadeiramente predomina é um corpo frio, mecânico, regido por leis biológicas, físicas e químicas...ideal e normativo, possuidor de uma estrutura e um modo de funcionamento específico... um corpo fracionado que passa a ser chamado de câncer, diabetes, AIDS .... um corpo científico. Assim, o ensino, ao dar ao aluno uma imagem científica do corpo, elimina os corpos não reconhecidos, reprimidos. O corpo-desejo, o corpoprazer, o corpo estético e tantos outros não são autorizados a se mostrarem nem serem mostrados.

A concepção do corpo-científico, corpo-objeto, corpo sem fronteiras porque sobre ele agimos, desnudamos, invadimos padroniza e coisifica o humano. Na medida em que negamos um corpo portador de sensação, de subjetividade estamos usando de mecanismos de defesa para não nos envolvermos, não sofrer a dor, a frustração e a impotência de algumas vezes não podermos aliviar a dor desse corpo. Essa consciência exigiria a percepção do tamanho de nossa onipotência, o reconhecimento da realidade e dos limites que ela impõe e a negação da racionalização, da busca de soluções mágicas para a resolução dos problemas.

Se a democracia é a liberdade de autonomia (TASSARA; DAMERGIAN, 1996), e implica na aceitação da diferença, a busca da padronização do humano, do enquadramento do ser humano nos códigos de pertinência da rotina hospitalar denota uma postura autoritária.

Os profissionais, arraigados às normas, expressam características de pessoas rígidas, obedientes, moralistas, aferradas à lei e que dificilmente exitam em hostilizar o outro. Ainda que, as normas sejam injustas, dominados pelo medo, não são capazes de criticá-las. Para MONEY-KIRLEY (1969) seriam pessoas cuja moral negaria a preservação e o bem do outro e, portanto, capazes essencialmente de culpa persecutória e de uma consciência autoritária em detrimento da humanista. A desumanidade aos nossos olhos em nome da lei. Lidamos com o humano sem conhecer o que de humano temos dentro de nós.

\section{Refletindo sobre caminhos para modifi- car a realidade!}

A lógica aristotélica segundo a qual A é A e não pode ser diferente de A (FROMM, 1972) caracteriza a lógica da dinâmica hospitalar centrada nas normas e rotinas invioláveis, incontestáveis, aplicadas sem discernimento a todos os pacientes e familiares como se representassem um agregado de 
objetos homogêneos. Tal lógica concebe a padronização do humano sendo, portanto, contrária à sua natureza.

"As estruturas sociais, são habitadas pelo sujeito psíquico, que traduz as singularidades, as especificidades de cada um, o sujeito vivido, histórico. Tais estruturas tornam-se palco da relações de vida e de morte através dos sujeitos que as habitam lhes dão significado, imprimindo nelas suas fantasias e desejos. Em decorrência das especificidades do ser humano, da necessidade de se considerar suas características particulares, de repeitar as singularidades que o definem como tal quando se pensa em vida social democrática, é preciso pensar na impossibilidade da igualdade, como é vulgar e falsamente concebida. A igualdade democrática (que na prática se traduz pela padronização dos indivíduos, pela homogeneização dos desejos), levada às últimas consequências, conduziria à eliminação do singular, do diferente, do distintivamente humano, da alteridade e dia verdadeira liberdade, que é a autonomia de cada um na produção de suas necessidades e desejos" (T ASSARA; DAMERGIAN, 1996).

Como participar e intervir criticamente na realidade hospitalar? Como preservar o respeito à nossa identidade e autonomia e a de nossos clientes e, assim , garantir a sobrevivência do humano? Como promover a eles a experiência do conforto?

Respostas a estas questões também não comportam normas, mas consciência crítica, atitude de contestação frente à realidade e a nós mesmos. Conhecer. modificar a realidade vigente mistificada pelos interesses dos dominadores, pela racionalização de nossas angústias e desejos requer o afastamento das camadas de entulho que nos impedem de visualizá-la. Reconhecer que somos humanos e que lidamos com o humano é fundamental.

As concepções de MONEY-KIRLEY (1969) mostram que o caminho para o humanismo está na compreensão de nós mesmos. Parte do princípio de que o conhecimento do que é genericamente denominado de humanidades, ou mais especificamente, o conhecimento de nós próprios e de outras pessoas, é capaz de modificar nossas preferências morais ou políticas, por meio dia substituição de falsas crenças por verdadeiras. Não é o conhecimento dia ciência que vai dar ao ser humano as condições para que pratique a moral e a política de um homem de bom, dia preservação do humano, mas este conhecimento precisa ser buscado dentro do próprio ser humano.

"Descobrimos que existe um elo causal entre a posse de uma certa espécie de consciência e a posse de uma certa espécie de sabedoria" (MONEY-
KIRLEY, 1969). Para o autor, a consciência humanista é a daqueles indivíduos relativamente isentos de pontos cegos e capazes de sentirem o que está dentro deles. Um afastamento do tipo autoritário de consciência e uma aproximação do humano é o efeito moral de qualquer aumento naquela espécie de sabedoria que consiste na vida intima ou no auto-conhecimento. O homem de bem seria aquele disciplinado, mas não rigidamente, que não se enquadra no autoritarismo e na estrita obediência às leis se a considerar injusta, que possui mais liberdade interior e responsabilidade em relação ao próximo e procura outras alternativas que não sejam ataque e destruição das pessoas. Portanto, a política do homem de bem é a democracia, aquela que comtempla os desejos do outro e a moral é calcada na capacidade de sentir culpa depressiva (baseada no amor e não no medo)

eque faz dele um verdadeiro humanista. O homem com predomínio de consciência do tipo humanista não tem grandes lapsos de desconhecimento a seu próprio respeito, é capaz de amar, e ter "insights" sobre si mesmo, preservar valores e sentimentos dos outros, é capaz de manter e preservar a humanidade, enfim é capaz de ser agente de mudança de si mesmo e de outros.

Trabalhos em pequenos grupos, que levem ao autoconhecimento e a conscientização de nosso papel na transformação da realidade poderão modificar as nossas preferências morais e politicas. Para BION (1969), aquele elemento que introduz a idéia nova traz a perspectiva de uma mudança catastrófica na medida em que romperia à tendência a conservação resultando em mudança e crescimento. A importância de líderes nas equipes de enfermagem que leiam e coloquem o grupo em contato com a realidade, destituídos de tendências centralizadoras, de direção e resolução dos problemas do grupo poderá promover o crescimento grupal. O autoconhecimento pode permitir-nos reconhecer os mecanismos de defesa que utilizamos ao vivenciar o processo de trabalho, ao entrarmos em contato com situações que mobilizam nossas ansiedades, ajudarnos a utilizar mecanismos menos lesivos, analisar criticamente a ideologia dos que representam o poder institucional e dos grupos de trabalho, romper com

o processo de identificação com o agressor, tomar consciência de nós mesmos e de nossos desejos evitando que ilusoriamente adotemos os desejos sociais como nossos. Os enfermeiros, ao se contraporem as identificações com o agressor, ao encontrarem o equilibrio entre as angústias e as demandas de cuidado, ao definirem as especificidades de seus fenômenos e pacturarem as metas assistenciais, limites e possibilidades com os clientes estarão mais próximos de reconhecer os desejos e a singularidade do sujeito, de respeitar as 
diferenças do outro, de preservar o contrato simbólico vindo a se contrapor à ausência de valores em busca de uma ordem fundamentada numa nova ética.

A mudança do status quo descrito neste trabalho só poderá ocorrer a partir de uma mudança interna dos indivíduos. Está em nós decidir se queremos reproduzir ou construir uma nova ordem social. Se não tivermos consciência de quem somos, de nossos limites, falhas e possibilidaddes será dificil reconhecer o outro e respeitar seus limites e suas diferenças. Jaques apud FORNARI (1989) nos mostrou que a mudança em um mecanismo cultural determina angústias que não podemos relacionar com o contexto concreto da mudança (ainda que tenha havido por parte de todos os interessados acordo sobre o interesse da mudança), as angústias mobilizadas tornam-se compreensivéis se forem relacionadas com o fato de que um mecanismo cultural institucionalizado, tem uma função de defesa contra as angústias inconscientes, independetemente do seu significado sobre o plano real. Resulta que as instituições de trabalho assumem a função de defesa contra as angústias primárias e fica demonstrado que a mudança nos mecanismos culturais de uma instituição mobiliza as angústias independentemente do risco concreto dia realidade implicado pela mudança. O problema dia mudança das instituições implica, portanto, toda uma problemática particular que lembra a dialética mudança-conservação é um suposto básico de grupo. Este, com efeito, exige o surgimento de instituições que reassegurem contra as angústias mobilizadas pela necessidade histórica de mudança. Entretanto, o fato de que a mudança de mecanismos culturais, na experiência de Jaques tenha mobilizado as angústias depressivas e persecutórias fez FORNARI (1989) supor a existência de um novo suposto básico que chamou de grupo conservação-mudança. Esse suposto se organiza nas instituições políticas. Assim, FORNARI (1989) ressaltou a importância que os indivíduos tem no interior das estruturas sociais nas quais as instituições se traduzem. Concluiu o autor que as mudanças de mecanismos culturais por mobilizarem as angústias elaboradas pelo suposto básico conservação-mudança, podem, praticamente, não mudar nada na vida das instituições se os homens não mudam. "C) fato de permanecerem os mesmos individuos pode explicar por que determinadas mudanças estruturais podem não apresentar efeito apreciável no plano da mudança efetiva. Ao contrário, a mudança, mesmo de um único indivíduo, pode determinar uma grande mudança nas instituições, mesmo que as estruturas $\mathrm{s}$ o c i a i s p e r m a $\mathrm{n}$ e ça $\mathrm{m}$ s e $\mathrm{m}$ mudanças"(FORNARI,1989). Transpondo estas concepções para a estrutura hospitalar, não podemos ficar por esperar a sua modificação, se não houver uma mudança nas estruturas básicas, entre elas, nos indivíduos que representam o serviço de enfermagem.

Por outro lado os pacientes e familiares ao se recusarem a aceitar os rótulos e as condições impostas a eles estarão também se recusando às imposições dos dominadores. Para TASSARA; DAMERGIAN (1996) a "utopia humanística depende da desmontagem do consenso ideológico dos dominados, tarefa hercúlea diante da assimetria de forças". Sabemos que a situação de saúde nesse país é catastrófica e que a maioria das pessoas que tentam chegar a um local de atendimento, quando conseguem, acreditam ter chegado ao "paraíso". Assim, para modificar esta consciência cabe a nós ajudá-los no processo de reconhecimento de que a saúde e a qualidade de assistência é um direito de todos os cidadãos, ao invés de nos tornarmos defensores do sistema.

\section{Concluindo!}

A experiência do conforto poderá surgir nos relacionamentos com aqueles que cuidam de nós. A presença solidária é a qualidade humana básica para estabelecermos as relações. As nossas demandas de atividades podem ser repensadas e redefinidas para evitarmos o desvio de funções, pois sabemos que não há defesa para o papel burocrático, mas para um campo com a perspectiva de interiorização de um modelo de construção de conhecimento e de uma consciência humanística. "Apesar de reconhecermos a determinação social e histórica que condiciona uma realidade assitencial próxima ao caos, acreditamos na possibilidade da sua superação inclusive pela intervenção profissional intencional, caminhando no sentido da qualificação do cuidar" (IDE, 1991).

\section{Apresentando as referências bibliográficas}

AMERICAN NURSES' ASSOCIATION - ANA. A statement on the scope of medical-surgical nursing practice. Kansas City, 1980. (Publ. MS-11).

ARRUDA, E. et al. Comfort: immigrant hispanic cancer patients' views. Cancer Nurs., v.15, n.6, p.387-94, 1992.

BION, R.W. Dinâmica de grupo: uma revisão In: KLEIN, M. et al. Temas de psicanálise aplicada. Rio de Janeiro, Zahar, 1969. cap. 7, p. 163-205.

BOTTORFF, J. The meaning of comfort: the lived experience of being comforted by a nurse. Canadá, s.d. /mimeografado/

CHAVES, E.C.; IDE, C.A.C. Singularidade dos sujeitos na vivência dos papéis sociais envolvidos na hospitalização. São Paulo, Escola de Enfermagem da USP, 1994. 11p. (mimeografado) 
COSTA, J.F. Psiquiatria burocrática - duas ou três coisas que sei dela. In: ARAGÃO, L.T. et al. Clínica do social. São Paulo, Escuta, 1991.p.39-74.

DU GAS, B.W. Enfermagem prática. 4.ed. Rio de Janeiro, Guanabara, 1984. cap.1 7, p.311-29: Necessidades de conforto, repouso e sono.

ELHART, D. et al. Princípios cientificos da enfermagem. Lisboa. Portuguesa de livros técnicos e científicos, 1983. cap. 4, p. 288-96: 0 âmbito de intervenção de enfermagem no apoio à adaptação.

FORNARI. F. Por uma psicanálise das instituições. In: KAES. R. et al. A instituição e as instituições. São Paulo, Casa o psicólogo, 1989. cap 4., p.81-107.

FRANCIS. G.M.: MUNJAS, B. Promoting psychological comfort. 2.ed. Dubuque, Brown, 1979. cap.4, p.57-61: Psychological comfort - nursing guidelines.

FROMM. E. Conciencia y sociedad industrial. In: FROMM,E. et al. La sociedad industrial contemporanea. Mexico, Siglo Veinteno Editores, 1972.

GOODNOW. M. La técnica de cuidar enfermos. 4.ed. Buenos Aires. P.R.O.C.M.O., 1950. cap.6, p.107-36: El comfort del paciente.

HORNEMANY, G.V. Procedimentos de enfermagem. São Paulo, EPU, 1977. cap.5, p.103-29: Mantendo a segurança e o conforto do paciente.

IDE. C.A.C. O ser "trabalhador de enfermagem" e o ser "doente": considerações sobre o desempenho de papéis sociais. Rev.Esc.Enf.USP, v.25, n. 1, p.103-12, 1991.

IDE. C.A.C. O ensino superior em enfermagem: o núcleo de significações para a expressão de uma nova ação pedagógica. 1995. 143p. Tese (Livre Docência). Escola de Enfermagem, Universidade de São Paulo.

JAQUES. E. Os sistemas sociais como defesa contra ansiedade persecutória e depressiva. In: KLEIN, M. et al. Temas de psicanálise aplicada. Rio de Janeiro, Zahar, 1969. cap. 8, p. 207-231.

JACOX, A.K. Key aspects of confort. In: FUNK, S. G. et al hey aspects of comfort: management of pain fatigue and nausea. New York, Springer. 1989. cap.2, p.8-21.
KAWAMOTO, E.E.; FORTES, J.I. Fundamentos de enfermagem. São Paulo, EPU, 1986. cap.6, p.30: Medidas de conforto e segurança do paciente.

KOLCABA, K.Y. Comfort as process and product merged in holistic nursing art. J.Holistic Nurs., v.13, n.2, p.117-31,1995.

MENZIES, I. O funcionamento das instituições como sistemas sociais de defesa contra a ansiedade. São Paulo. Escola de Administração de Empresas da FGV, s.d./ mimeografado/

MONEY-KIRLEY, R.E. Psicanálise e ética. In: KLEIN, M. et al. Temas de psicanálise aplicada. Rio de Janeiro, Zahar, 1969.

MORSE, J.M. et al. The phenomenology of comfort. J.Adv.Nurs., v.20, n.1, p.189-95, 1994

MUSSI, F. C. Conforto : significados e necessidades na perspectiva o paciente com infarto agudo do miocárdio. São Paulo, 1994. 102p. Dissertação (Mestrado) - Escola de Enfermagem, Universidade de São Paulo.

NASCIMENTO, E.S. Poder e cultura na organizações. Rev.Paul.Enf., v.10, n.1, 1991.p.67-72.

NITHINGALE, F. Notes on nursing. London, Harrison, 1859.

OLIVEIRA, C.; MUSSI, F.C. O conforto na perspectiva de familiares de pacientes em estado crítico. São Paulo, Escola de Enfermagem do HIAE, 1996.45p. (mimeografado)

ORLANDO, I.J. O relacionamento dinâmico enfermeiropaciente. São Paulo EPU, 1978. cap.1, p.7-11: A atividade do enfermeiro profissional.

RODRIGUES, A.M. Poder e cultura na organizações. Rev.Paul.Enf., v.10, n.1, 1991.p.67-72.

SORRENTINO, S.A. Mosby's textbook for nursing assistants. 2.ed. Saint Louis, Mosby, 1987. cáp.11, p.53-160: The patient unit.

TASSARA, E.T.O; DAMERGIAN,S. Para um novo humanismo: contribuições da psicologia social. Rev.Est. Avanç. v.10, n.28, p.291-316, 1996 